\title{
Small-Molecules Targeting Sirtuin 1: A Patent Review (2012-2015)
}

\author{
Alessandra Graziadio, Alessandra Locatelli*, Rita Morigi and Mirella Rambaldi
}

The Department of Pharmacy and Biotechnology FaBiT, University of Bologna, Via Belmeloro, 6, Bologna, Italy

\begin{abstract}
Sirtuins are a family of enzymes, which govern genome regulation, stress response, metabolic homeostasis and lifespan. Among all the discovered human isoforms (SIRT1-7), SIRT1 emerged as a promising molecular target for the treatment of several diseases. The SIRT1 activators have shown beneficial effects in diabetes, obesity, disorders related to aging, cardiovascular and neurodegenerative diseases. On the other hand, SIRT1 inhibition could be applied in anticancer therapy. This review is focused on patents regarding small molecules targeting SIRT1 registered from 2012 to 2015 . The chemical formula, the activation and/or inhibition activity and the application of the most active compounds are considered.
\end{abstract}

Keywords: SIRTs; Modulation; SIRT1-inhibitors; Anticancer; SIRT1activators; Identification assays; Metabolic disorders; Resveratrol

\section{Introduction}

Sirtuins are a family of enzymes, widely distributed in organisms ranging from archaea to humans, involved in various biological processes, such as transcription, cell survival, genome stability and instability, DNA damage and repair, and longevity [1]. The silent information regulator 2 (Sir2) was the first sirtuin identified in yeast, other examples are the bacterial CobB sirtuins (isoforms Sir2Tm and Rv1151c), the archaeal sirtuins (Sir2Af1 and Sir2Af2), while SIRTs1-7 are present in mammals [2].

Sirtuins share a highly conserved catalytic core but differ in $\mathrm{N}$ and C-terminal extensions. The catalytic core consists of two domains: a larger Rossmann-fold domain typical for $\mathrm{NAD}^{+}$binding proteins and a smaller, more variable zinc-binding domain. The zinc ion is coordinated by four invariant cysteines and appears essential for the stability of the protein. The acetylated substrate and the $\mathrm{NAD}^{+} \mathrm{co}-$ substrate bind in a cleft between the two domains thereby inducing closure of the active site and stabilization of a so-called cofactor binding loop. In a productive conformation, the nicotinamide moiety of $\mathrm{NAD}^{+}$ is buried in the highly conserved C pocket [3].

These enzymes catalyze the deacetylation of specific $\mathrm{N}^{\varepsilon}$-acetyllysines (AcK) on several protein substrates, such as histones, transcription factors and enzymes, utilizing nicotinamide adenine dinucleotide $\left(\mathrm{NAD}^{+}\right)$as co-substrate. The enzymatic reaction involves the acetyl group transfer from AcK to ADP-ribose moiety of $\mathrm{NAD}^{+}$ coupled with cleavage of the nicotinamide from $\mathrm{NAD}^{+}$and consequent production of the deacetylated protein and 2'-O-acetyl-ADP-ribose (2'-OAcADPR) [4] (Figure 1).

The seven sirtuins (SIRT1-SIRT7) present in humans have differential cellular localization. SIRT1, the human Sir2 homolog, is located mainly in the nucleus; SIRT2 is predominantly in cytoplasm but may also be present in the nucleus. SIRT6 and SIRT7 are present in the nucleus, while SIRT3, SIRT4, and SIRT5 are mithocondrial $[5,6]$. SIRT3 is ubiquitously expressed, especially in metabolically active tissues. SIRT3 acts as a mitochondrial deacetylase, while SIRT5 acts as both a desuccinylase and demalonylase [7]. This family of enzymes governs genome regulation, stress response, metabolic homeostasis and lifespan.

In particular SIRT1 exerts several effects in genome regulation, such as promoting the folding of chromatin into a more tightly packed form called heterochromatin, which is associated with histone hypoacetylation and gene repression.

Moreover SIRT1 may play a relevant role in the control of metabolism and cellular differentiation, regulating negatively the activity of the histone acetyltransferase p300, a limiting transcriptional cofactor.

One of the most interesting target of SIRT1 is the tumor suppressor p53. Indeed it has been shown that SIRT1 deacetylates several lysine residues of $\mathrm{p} 53$, thus leading to apoptosis suppression in response to oxidative stress and DNA damage, and therefore to an increase of cell survival.

Another alternative pathway by which SIRT1 increases cell survival is through the regulation of FOXO (Forkhead box O) transcription factors. There are four FOXOs and so far SIRT1 has been shown to deacetylate three isoform: Foxo1, Foxo3a and Foxo4. SIRT1 also affects Foxo3a function in neurons and fibroblasts, reducing apoptosis in response to stress stimuli, but increasing in expression of DNA repair and cell-cycle checkpoint genes.

SIRT1 seems to play a key role also in regulating metabolism in response to dietary changes, in fact it promotes fat mobilization in white adipose tissue by binding to and repressing genes involved in adipogenesis, such as PPAR- $\gamma$ (peroxisome proliferator-activated receptor $\gamma$ ) and aP2 (fatty acid binding protein), and also by quenching the PPAR- $\gamma$ cofactors NCoR (nuclear receptor co-repressor) and SMRT (silencing mediator of retinoid and thyroid hormone receptors) [8].

Considering the molecular pathways described above, in which SIRT1 is involved, compounds able to potentiate SIRT1 effects can be useful for several diseases, such as cardiovascular and neurodegenerative diseases, diabetes, obesity, inflammation and disorders related to aging. Instead, SIRT1 inhibition has been proposed for the treatment of immunodeficiency virus infections and of parasitic diseases, as well as to stimulate appetite, and/or weight gain in metabolic disorders. Both SIRT1 activation and inhibition have been proposed in cancer therapy, as well as, SIRT2 inhibition [9].

${ }^{*}$ Corresponding author: Alessandra Locatelli, The Department of Pharmacy and Biotechnology FaBiT, University of Bologna, Via Belmeloro, 6, Bologna, Italy, Tel: +390512099700; E-mail: alessandra.locatelli@unibo.it

Received June 14, 2016; Accepted June 20, 2016; Published June 24, 2016

Citation: Graziadio A, Locatelli A, Morigi R, Rambaldi M (2016) Small-Molecules Targeting Sirtuin 1: A Patent Review (2012-2015). Med chem (Los Angeles) 6: 411421. doi:10.4172/2161-0444.1000378

Copyright: ( 2016 Graziadio A, et al. This is an open-access article distributed under the terms of the Creative Commons Attribution License, which permits unrestricted use, distribution, and reproduction in any medium, provided the original author and source are credited. 


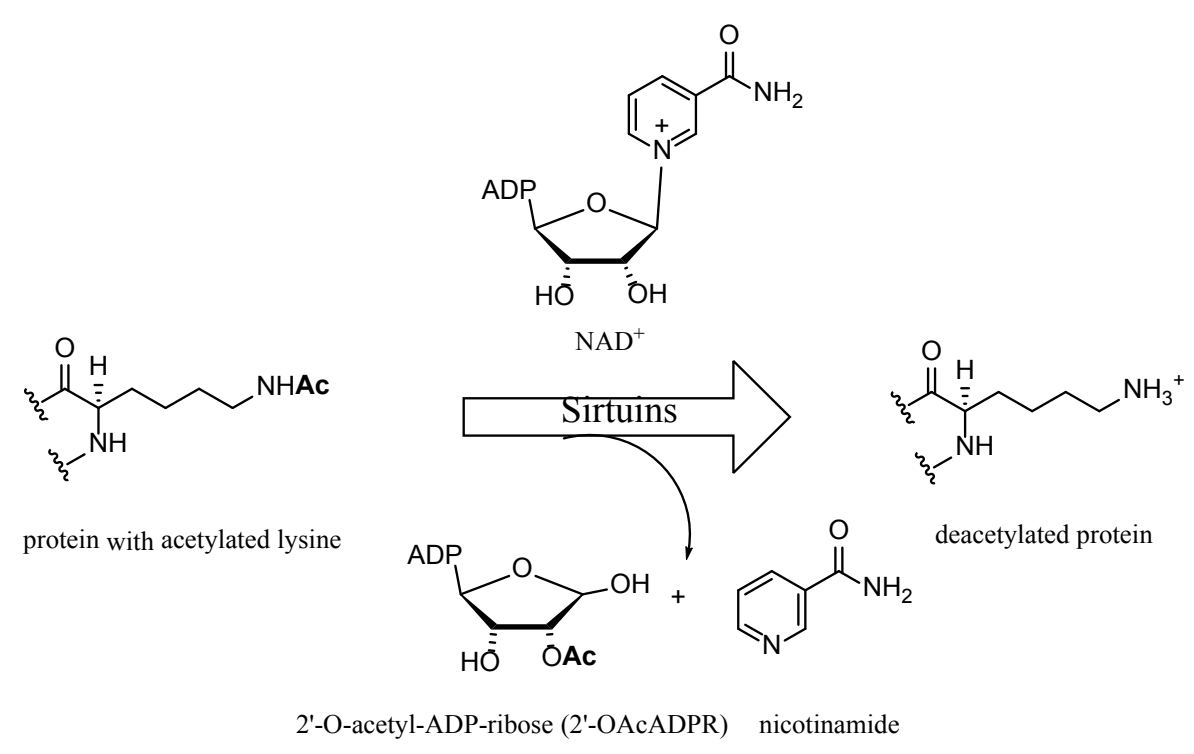

Figure 1: Mechanism of SIRTs deacetylation.<smiles>Oc1ccc(/C=C/c2cc(O)cc(O)c2)cc1</smiles>

Resveratrol<smiles>Oc1cc(O)cc(C=Cc2ccccc2)c1</smiles>

Pinosylvin<smiles>OCc1c[nH]c2ccccc12</smiles>

$\mathrm{I} 3 \mathrm{C}$<smiles>O=C(Nc1ccccc1-c1cn2c(CN3CCNCC3)csc2n1)c1cnc2ccccc2n1</smiles>

SRT1720

Figure 2: Examples of SIRT1 activators.

Based on the large variety of SIRTs enzymatic functions, a huge amount of patents about sirtuin modulators and their possible therapeutic applications have been registered. In this review, we focused the attention on small molecules targeting SIRT1 and on their applications. Moreover, the mass spectroscopy and fluorescent based methodologies applied for the development of both SIRT1 activators and inhibitors are reported. For the patent search, the Espacenet and the Scifinder databases have been used, applying essentially the keywords "sirtuin" and the range from 2012 to 2015. Only patents published in English were considered.

\section{Uses of Sirtuin Modulators}

The SIRTs modulators include both activators and inhibitors. Until now, the activators have been described only for SIRT1. Some of these important activators (Figure 2 and Table 1) are: resveratrol (3,5,4'-trihydroxystilbene), present in several plants in particular grapes, blueberries and raspberries [10]; pinosylvin, a pre-infectious stilbenoid toxin present in the heartwood of Pinaceae [11]; the imidazothiazole derivate SRT1720, an experimental drug that has been studied by Sirtris Pharmaceuticals [12] and the indole-3-carbinol (I3C), a natural product of Brassica vegetables [13].

Many inhibitors have been reported for all SIRTs [14], some examples are reported in Figure 3 and Table 1.

Many SIRT1 activators, described in the reported patents, may be used for cardiovascular diseases. Among the cardiovascular diseases, there are cardiac arrhythmias, such as Brugada syndrome, still lacking an effective therapy. The Brugada syndrome, a congenital arrhythmia, 
Citation: Graziadio A, Locatelli A, Morigi R, Rambaldi M (2016) Small-Molecules Targeting Sirtuin 1: A Patent Review (2012-2015). Med chem (Los Angeles) 6: 411-421. doi:10.4172/2161-0444.1000378

\begin{tabular}{|c|c|c|}
\hline SIRT1 Activators & SIRT1/2 Inhibitors & Potential Applications* \\
\hline Resveratrol & & - lifespan extension \\
\hline Pinosylvin & & - metabolic disorders \\
\hline SRT1720 & & - metabolic disorders \\
\hline \multirow[t]{8}{*}{ I3C } & & - metabolic disorders \\
\hline & Nicotinamide (SIRT1) & - treatment of cancers \\
\hline & Sirtinol (SIRT1/2) & $\begin{array}{l}\text { - treatment of breast, lung and prostate cancer } \\
\text { - treatment or prevention of leishmaniosis }\end{array}$ \\
\hline & EX-527 (SIRT1) & $\begin{array}{c}\text { - chemical tools to study the biology of SIRT1 and to explore } \\
\text { therapeutic uses for SIRT inhibitors }\end{array}$ \\
\hline & Cambinol (SIRT1/2) & - treatment of Burkitt lymphoma \\
\hline & Splitomicin (SIRT1) & - treatment of cancers \\
\hline & Thiobarbiturates (SIRT1/2) & - treatment of cancers \\
\hline & Tenovin-1 (SIRT1/2) & - treatment of cancers \\
\hline Quinazolinone derivatives 1 & & - metabolic disorders \\
\hline Strigolactone analogues GR24, 2 & & - metabolic disorders \\
\hline \multirow[t]{2}{*}{ Pyridine dicarboxamide derivatives 3-6 } & & n.d. \\
\hline & $\begin{array}{l}\text { Pyridine dicarboxamide derivative } 7 \\
\text { (SIRT1) }\end{array}$ & n.d. \\
\hline Imidazo-pyridazine derivatives 8-10, 12 & & n.d. \\
\hline Pyrazolo-pyrimidine derivative 11 & & n.d. \\
\hline Substituted bridged urea analogs $13-15$ & & n.d. \\
\hline \multirow[t]{2}{*}{ Carboxylated stilbene derivative 16} & & n.d. \\
\hline & $\begin{array}{l}\text { Substituted thieno[3,2-d]pyrimidine-6- } \\
\text { carboxamide derivatives } 17-18\end{array}$ & n.d. \\
\hline
\end{tabular}

"n.d.: Potential applications were not yet evaluated in the considered patents

Table 1: Potential applications of compounds targeting SIRT1.<smiles>NC(=O)c1cccnc1</smiles>

Nicotinamide (SIRT1)<smiles>CC(NC(=O)c1ccccc1/N=C/c1cccc2ccccc12)c1ccccc1</smiles>

(SIRT1/2)<smiles>NC(=O)[C@H]1CCCc2c1[nH]c1ccc(Cl)cc21</smiles>

EX-527

(SIRT1)<smiles>O=c1[nH]c(=S)[nH]c(-c2ccccc2)c1Cc1c(O)ccc2ccccc12</smiles>

Cambinol (SIRT1)<smiles>O=C1CCc2c(ccc3ccccc23)O1</smiles>

Splitomicin (SIRT1)<smiles>O=C1NC(=S)NC(=O)C1=Cc1cc2ccccc2[nH]1</smiles>

Indole-substituted thiobarbiturate (SIRT1/2)<smiles>CC(=O)Nc1ccc(NC(=S)NC(=O)c2ccc(C(C)(C)C)cc2)cc1</smiles>

(SIRT1/2)

Figure 3: Examples of SIRT1 and /or SIRT2 inhibitors.

is associated with decreased expression or activity of sodium channels (Navl.5). Since SIRT1 deacetylates Navl.5 and increases sodium current, compounds that increase the activity and/or expression of SIRT1 are very effective [15]. Moreover, activators have been proposed for the treatment of neurodegenerative diseases (for examples Alzheimer's, Parkinson's and Huntington's diseases, amyotrophic lateral sclerosis, ocular diseases) and traumatic or mechanical injury to the central or peripheral nervous system [16-19].

Sirtuin modulators, described in many inventions, for their anticoagulant and antithrombotic action may be used to treat blood coagulation disorders, such as myocardial infarction, stroke, or 
pulmonary embolism. As the sirtuins can play a key role in obesity, small molecules that modulate their activity may be used in metabolic disorders. It is known for over 80 years, that caloric restriction improves the health and extends the lifespan of mammals. However, the dietary restriction did not extend lifespan when sirtuins were deleted. This has led to suppose that the extension of life may be due to induction of SIRT1 expression, thus prompting the investigators to search activator molecules. In metabolic pathways, SIRT1 controls adipocyte cytokines expression, fat cells maturation, insulin secretion, plasma glucose levels, cholesterol and lipid homeostasis, and mitochondrial energy capacity. SIRT1 regulates the lifespan through several mechanisms. One of the most important is the interaction with coactivators, such as PGC-1 family, that have a key role in the homeostasis of glucose, lipids, and energy and are involved in disorders such as obesity, diabetes, neurodegeneration, and cardiomyopathy. SIRT1 deacetylates PGC1 , increasing its activity, and thus acting as a PGC-1 modulator [2023]. Moreover SIRT1 is highly expressed in the hypothalamus, where regulates energy homeostasis and induces beneficial effects in the caloric restriction $[24,25]$.

Sirtuin activators could find applications in inflammatory, allergic and respiratory disorders. Moreover, they may be useful for improving physical performances in sports activities, enhancing energy and blood oxygen levels. They reduce muscle fatigue and stress, increasing muscle ATP levels and reducing lactic acid in blood, thus improving cardiovascular function. They are also effective in the treatment of pathological conditions affecting the muscle, such as acute sarcopenia, muscle atrophy or cachexia [26]. Many inventions provide indications about the increase of mitochondrial activity with sirtuin activators.

Compounds that modulate the level and/or activity of both SIRT1 and SIRT2 are considerate useful tools against tumors such as bladder, breast, cervix, head and neck, lung, colorectal, hepatocellular, pancreatic, prostate and renal carcinoma, chronic lymphocytic and myelogenous leukemia, multiple myeloma, non-Hodgkin's lymphoma, brain tumors, melanoma, and soft tissue sarcomas [27,28].

The activity of the modulators on viral infections is not yet fully clarified, in fact both activators and inhibitors are reported for their ability to counteract the viral infections [29,30]. In two patents [29,31], Shenk et al. reported that known activators, such as polyhydroxy stilbenes, flavonoids or polyhydroxy chalcones, inhibited viral replication. The patents reported that resveratrol inhibited the effects produced by human cytomegalovirus (HCMV) on the viral replication. The same effect was also reported for another activator, CAY10602 [32]. The patent [30] reported that SIRT1 inhibitors or SIRT1/SIRT2 dual inhibitors reduced replication of HCMV and other viruses.

\section{Methodologies for Sirts Modulators Identification}

A number of biological assays have been validated in order to identify compounds able to modulate sirtuins enzymatic activity. Generally, an assay consists in measuring the ability of a test agent to modulate the deacetylation of a peptide substrate by a sirtuin. Since p53 was the first non-histone sirtuin target discovered and multiple lysine residues on p53 can be deacetylated by sirtuins [33], a p53 sequence containing the acetylated lysine is used as peptide substrate. Assays may be conducted in a cell free or cell based system. Peptide substrates are acetylated using radiolabeled acetate. After incubation with sirtuin and test agent, the radioactive signal of the remaining peptide substrate is quantified [34]. Another assay is based on the release of nicotinamide from the $\mathrm{NAD}^{+}$co-substrate, selectively blocked by a resin $[10,35]$. Another screening assay detects 2'-OAcADPR, produced by sirtuin- mediated NAD-dependent deacetylation, in equimolar quantities with the deacetylated peptide (see Figure 1). An increase in 2'-OAcADPR levels indicates that the test agent stimulates deacetylation, while a decrease indicates an inhibitory effect [36].

Mass spectrometry based [37] or fluorescence based assays [36] may be also used to determine sirtuin activity. An assay based on the fluorescence resonance energy transfer [FRET] technology uses a cryptate-labeled acetyl-p53 peptide (donor) and a d2-labeled antiacetyl-p53 antibody (acceptor). In this method, deacetylase activity causes a decrease in FRET signal $[36,38]$. Others assays include radioimmunoassays (RIA), scintillation proximity assays, HPLC based assays and reporter gene assays (e.g., for transcription factor targets) [39].

For the mass spectrometry assay, preferred substrates are acetylated peptides (such as peptides of p53, the Fluor de Lys-SIRT1 and peptides from human histones $\mathrm{H} 3$ and $\mathrm{H} 4$ ). The sirtuin may be SIRT1, Sir2, SIRT3, or N-terminus portions (amino acids 1-176 or 1-255 of SIRT1; amino acids 1-174 or 1-252 of Sir2), since it has been seen that compounds interact with the $\mathrm{N}$-terminus portion. The cells are incubated with the test compound and the substrate for about 1-3 hours. Nicotinamide is added as a negative control at the beginning of the reaction, since it inhibits deacetylase activity occupying the co-substrate-binding pocket. As positive control for determining the amount of deacetylation of the substrate at a given time point within the linear range, $10 \mathrm{nM}$ of sirtuin protein in $1 \mu \mathrm{L}$ of DMSO is used. This time point is the same as that used for test compounds and, within the linear range, the endpoint represents a change in enzymatic reaction kinetics [36].

In the examined patents, the degree of SIRT1 deacetylation activated by a test agent is expressed as $\mathrm{EC}_{1.5}$ (i.e., the concentration of compound required to increase SIRT 1 activity by $50 \%$ compared to the control), or as percentage of maximum activation (i.e., the maximum activity achieved relative to control (100\%) at the highest concentration of the test compound). To measure the degree of activation induced by a compound, it is used also half maximal effective activating concentration $\left(\mathrm{AC}_{50}\right)$, i.e., the concentration which induces an enzymatic activation response halfway between the baseline and maximum, following the required incubation time.

\section{SIRT1 Activators}

In 2012, $\mathrm{Vu}$ patented quinazolinone derivatives as sirtuin modulators [40]. The compounds are represented by the general formula reported in Figure 4 and Table 1, where $\mathrm{R}_{1}$ is a heterocycle or a substituted heterocycle; $\mathrm{X}$ is an amide; $\mathrm{R}_{2}$ is a $\mathrm{m}$-trifluoromethylphenyl or a m-trifluoromethoxyphenyl moiety and $\mathrm{R}_{3}$ is a $\mathrm{C}_{1}-\mathrm{C}_{4}$ alkyl group such as methyl. The patent reported also the synthesis using conventional techniques, from readily available starting materials. Sirtuin modulators were identified using the mass spectrometry based assay. The substrate was a 20 amino acid peptide having an acetylated lysine, and labelled with the fluorophore 5-carboxytetramethylrhodamine (5TMR) (excitation $540 \mathrm{~nm} / \mathrm{emission} 580 \mathrm{~nm}$ ) at the C-terminus. The compound 1 (Figure 4 and Table 1) was the most active of the series, with an $\mathrm{EC}_{1.5}$ value for SIRT1 activation $\leqq 50 \mu \mathrm{M}$ and the percent maximum fold activation (FOLD) $>150 \%$, whereas it showed an $\mathrm{IC}_{50}$ value $<10 \mu \mathrm{M}$ for SIRT2 inhibition.

In 2012, Laakso et al. made an application [41] for the treatment of metabolic disorders, such as type 2 diabetes or obesity, with a terpenoid lactone bearing a 5-alkenyloxy-furan-2-one group, analogue of strigolactone GR24 (Figure 5 and Table 1) [42]. The patent also 


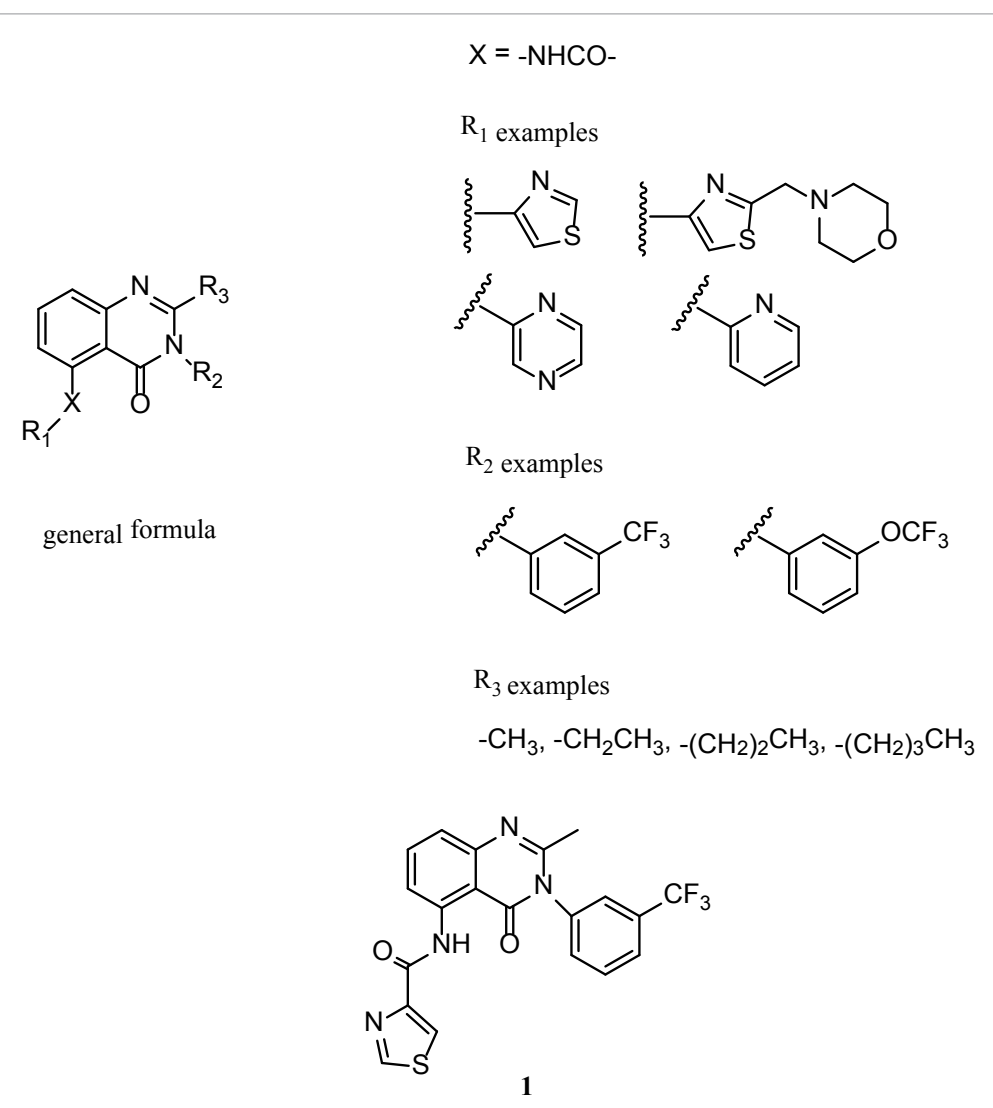

Figure 4: Quinazolinone derivatiives.

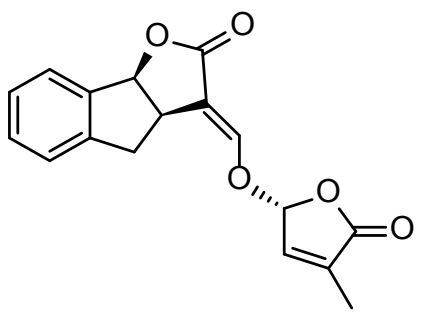

$(+)-G R 24$

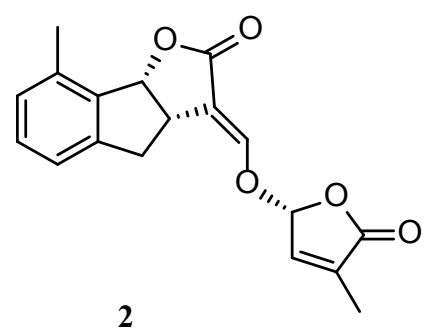

2

Figure 5: Strigolactone analogues.

presented some terpenoid lactones as novel SIRT1 activators, that may be used alone or in combination with resveratrol or pinosylvin. On the other hand, the literature reports the use of different associations, as food supplement, to increase the action of SIRT1. An example was reported in the patent [43], which described a food supplement, consisting of resveratrol, nicotinic acid or a precursor of nicotinic acid, and D-ribose. The application of Laakso, in addition to numerous assays on GR24, shows the activity of the new derivatives on SIRT1. Since the treatment of adipocytes with GR24 increased the SIRT1 expression, a first assay was conducted processing 3T3-L1 preadipocytes with $60 \mu \mathrm{M}$ of compounds for 24 hours and compared to control (100\%) and to GR24. The change in SIRT1 protein expression was produced from compound 2 (Figure 5 and Table 1) with percentage changes of $327 \%$ and $48 \%$ compared with control (100\%) and GR24, respectively. Since PGC-1 is an indicator of SIRT1 activity [44], an immunoblot test evaluating the percentage changes in PGC-1 $\alpha$ expression in 3T3-L1 preadipocytes, was conducted. The results were in agreement with the previous assay.

In 2013, Larsen et al. patented new substituted pyridine dicarboxamides, as sirtuin modulators [45]. The SIRT1 activation by test compounds was measured as a FRET induced UV signal, in presence of the acetylated and labelled with a fluorescent probe peptide substrate, where maximal signal (100\%) corresponds to no activation. The detection of the activity involves quantification of the deacetylation process using nicotinamide, as inhibition control, and the compound SRT1720 [12], as activation control. Compounds 3, 4, 5 and 6 (Figure 6 and Table 1) showed clear activation, having $\mathrm{AC}_{50}$ values in the micro molar range, whereas compound 7 (Figure 6 and Table 1) showed clear inhibition of SIRT1 deacetylating activity with an $\mathrm{IC}_{50}$ value of $0.5 \mu \mathrm{M}$. The patent also studied ADME profiling of SIRT1 activators in order to evaluate the pharmacokinetic properties of the most interesting compounds. 
<smiles>NC(=O)c1ccc(NC(=O)c2ccccc2O)nc1</smiles>

3 (activator)<smiles>NC(=O)c1ccc(C(=O)Nc2ccc(O)cc2O)nc1</smiles>

5 (activator)<smiles>NC(=O)c1ccc(C(=O)Nc2ccc(O)cc2O)nc1</smiles><smiles>NC(=O)c1cccc(C(=O)Nc2ccc(O)cc2O)n1</smiles>

6 (activator)<smiles>NC(=O)c1cc(C(=O)Nc2ccccc2O)c[nH]1</smiles>

7 (inhibitor)

Figure 6: Dicarboxamides as sirtuin modulators.<smiles>O=C(Nc1ccc2ncc(-c3ccccc3Cl)n2n1)c1ncccn1</smiles>

8<smiles>O=C(Nc1cccc(N2CCOCC2)n1)c1ccc2ncc(-c3cccc(C(F)(F)F)c3)n2n1</smiles>

10<smiles>O=C(Nc1ccnc(C2CCOCC2)c1)c1ccc2ncc(-c3cccc(C(F)(F)F)c3)n2n1</smiles>

9<smiles>O=C(Nc1ccnc2cc(-c3ccccc3C(F)(F)F)nn12)c1cccc(OCC(O)CO)n1</smiles>

11

Figure 7: Imidazo-pyridazine and pyrazolo-pyrimidine derivatives.

In 2013, Blum et al. reported two patents [46,47] including several aza-heterocycles, in particular imidazo-pyridazines, triazolopyridazines and pyrazolo-pyrimidines, as sirtuin modulators. In another patent of 2013 [48], Casaubun et al. reported a large library of similar aza-heterocycles. SIRT1 activating compounds were identified using two assays, similar to those described previously. The TAMRA based mass spectrometry assay used a peptide having sequence: AcEE-K(biotin)-GQSTSSHSK(Ac)NleSTEG-K(5TMR)-EE-NH (SEQ $_{2}$ ID NO: 1), wherein $\mathrm{K}(\mathrm{Ac})$ is an acetylated lysine residue and Nle is a norleucine. The peptide was labeled with the fluorophore 5TMR at the C-terminus. The Trp based assay utilized a peptide having an amino acid residues as follows: Ac- $\mathrm{R}-\mathrm{H}-\mathrm{K}-\mathrm{K}(\mathrm{Ac})-\mathrm{W}-\mathrm{NH}_{2}$ (SEQ ID NO: 2). The activity is expressed as $\mathrm{EC}_{1.5}$ values that represent the concentration of test compounds that results in $150 \%$ activation of SIRT1. In the series of imidazo-pyridazines [46], the most active compounds, in TAMRA assay, were 8, 9 and 10 (Figure 7 and Table 1) with $\mathrm{EC}_{15}$ values $<1 \mu \mathrm{M}$ and FOLD Act $>350 \%$. Whereas in the series of pyrazolo-pyrimidines [47], the most active compound was 11 (both enantiomers) (Figure 7 and Table 1) with $\mathrm{EC}_{1.5}$ values $<1 \mu \mathrm{M}$ for both TAMRA and Trp assays.

The library of Casaubon et al. patent [48] included 1099 compounds, of these, 76 compounds had an $\mathrm{EC}_{1.5}$ value $<1 \mu \mathrm{M}$ and FOLD Act $>350 \%$ in both assays (TAMRA and Trp). The derivate 12 (Figure 8 and Table 1 ) is one of the most active of the library compounds, and its synthesis is reported as example in Scheme A.

As described in the above cited patent [48], 6-chloro-4- 
<smiles>Cc1nc2c(C)cc(-c3ccccc3C(F)(F)F)nn2c1C(=O)Nc1cccnn1</smiles>

Figure 8: Imidazo-pyridazine derivative.<smiles>CCOC(=O)C(C)C(C)C(C)=O</smiles><smiles></smiles><smiles>CCOC(=O)c1c(C)nc2c(C)cc(-c3ccccc3C(F)(F)F)nn12</smiles><smiles>Nc1ccnn1Cl</smiles><smiles></smiles>

Scheme A: Synthesis of compound 12.

methylpyridazin-3-amine (a) was allowed to react with ethyl 2-chloro3-oxobutanoate in ethanol as solvent under reflux for $48 \mathrm{~h}$, to yield ethyl 6-chloro-2,8-dimethylimidazo[1,2-b]pyridazine-3-carboxylate (b). This compound was treated with 2-(trifluoromethyl)phenylboronic acid, cesium carbonate and $\mathrm{Pd}\left(\mathrm{PPh}_{3}\right)_{4}$ in dioxane and water and heated to $75^{\circ} \mathrm{C}$ for $5 \mathrm{~h}$, to give ethyl 2,8-dimethyl-6-(2-trifluoromethyl) phenyl)imidazo[1,2-b]pyridazine-3-carboxylate (c). After ester hydrolyses, the coupling reaction was performed by adding 3-aminopyridazine hydrochloride, N,N-diisopropylethylamine (DIEA) and $N$-[(dimethylamino)-1H-1,2,3-triazolo-[4,5-b]pyridin1-ylmethylene]- $N$-methylmethanaminium hexafluorophosphate $\mathrm{N}$-oxide (HATU) as coupling reagent. The resulting reaction mixture was warmed to $60^{\circ} \mathrm{C}$ for $3.5 \mathrm{~h}$, and subsequently the obtained crude product was purified by column chromatography to afford compound $\mathbf{1 2 .}$

In 2014, Blum et al. patented novel substituted bridged urea analogues and their preparation, as sirtuin modulators [49]. Some of the most active compounds $(13,14$ and 15) are reported in Figure 9 and Table 1.

The patent studied also the identification and characterization of the key functional regions of hSIRT1, by means proton-deuteron exchange mass spectrometry (HDX-MS). Indeed the rate of $\mathrm{H}-\mathrm{D}$ exchange is highly dependent on the dynamic properties of the protein, with faster exchange occurring at solvent exposed and/or flexible regions and slower exchange occurring at the more buried and/or structurally rigid regions [50].

Considering that resveratrol is a SIRT1 activator, the study of stilbene and polyphenol derivatives, as sirtuin modulators, is substantially increased. In 2014, Bitzer et al. patented an invention concerning carboxylated stilbene derivatives and their use for treatment of several diseases, in particular treatment of metabolic disorders and neurodegenerative diseases [51]. Compounds of the invention are potent agonists of sirtuins, in particular SIRT1, 2 and/or 3, with increased activity compared to resveratrol. Moreover, they significantly enhance AMPK phosphorylation and the number of mitochondria in cells. The compounds were tested in vitro and compared with resveratrol for SIRT1 activation. The most active compound of the series (compound 16, Figure 10 and Table 1) produced a fold increase in SIRT1 activity versus control of 23.9 (control=1). This compound was also selected for other experiments. In the quantification of the SIRT1 agonistic effect, dose response, EC300 value (i.e., the concentration that gave 3 -times the basal response of the enzyme) was $2 \mu \mathrm{M}$, versus a value $>30 \mu \mathrm{M}$ for resveratrol. Moreover, the selectivity on SIRT1, SIRT2 and SIRT3 was investigated. The results demonstrate that compound $\mathbf{1 6}$ has an agonistic activity on all three isoforms with similar dose-response behaviours on SIRT1 and SIRT2. The dose-response effect is slightly lesser on SIRT3. 
<smiles>O=C(Nc1cccc(-c2cnco2)c1)N1C[C@@H]2CCN1c1ccc(-c3cccc(C(F)(F)F)c3)nc12</smiles>

13<smiles></smiles>

14<smiles>CCn1ncc2c(NC(=O)N3c4nc(-c5cccc(C(F)(F)F)c5)ccc4N4CC[C@H]3C4)cccc21</smiles>

Figure 9: Substituted bridged urea analogues.<smiles>CCOC(=O)c1c(O)cccc1/C=C/c1ccc(OCC)cc1</smiles>

16

Figure 10: Stilbene derivative.

The presence of SIRTs modulating ingredients in several foods has led researchers to study new natural extracts. The patent of Pan et al. [52] involves the use of isoflavones, included in the diet, to regulate SIRTs expression and activity. The invention of Buchwald-Werner et al. [53] reported that extracts of Mangifera Indica (Mango) are SIRT1 activators.

\section{SIRT1 Inhibitors}

Since the catalytic site of the diverse SIRT isoforms is highly conserved, in recent years several reports on SIRT1 and SIRT2 inhibitors have been published [54-56]. Interestingly, the simultaneous inhibition of SIRT1 and SIRT2 may cause cancer cell death, since p53 sirtuin-mediated deacetylation is inhibited, whereas the independent inhibition of SIRT1 and SIRT2 would be insufficient [55].

In 2014, Blum et al. [57] reported about two hundred substituted thieno[3,2-d]pyrimidine-6-carboxamide derivatives and analogues as SIRT1, SIRT2 and SIRT3 inhibitors for treating cancer, neurodegenerative disease and inflammation. Compounds of the invention are represented by general formulas reported in Figure 11 and Table 1.

Some novel derivatives were evaluated, in a biochemical assay, for their ability to inhibit the deacetylation of a peptide substrate (AcRHKK ${ }^{\mathrm{Ac}} \mathrm{W}-\mathrm{NH}_{2}$ ) in presence of SIRT1, SIRT2 or SIRT3. Compound 17 (Figure 11 and Table 1) displayed excellent potency with an $\mathrm{IC}_{50}$ of $4 \mathrm{nM}$ for SIRT1 and SIRT3 and of $3 \mathrm{nM}$ for SIRT2. Replacement of the piperidine with a piperazine reduced only slightly the potency against SIRT2, whereas SIRT1 and SIRT3 inhibition was reduced about 7-8 fold. The effect of replacing the thiophene with a phenyl ring, both in piperidine and piperazine analogues, showed a decrease in SIRT1 and SIRT2 inhibition and an improvement in SIRT3 inhibition. Since compound 17 was lacking of drug-like properties its development failed, and to explore the possibility to improve the physiochemical features, a series of analogues were synthetized and evaluated. In a first series, the replacement of the ethylamide group with tert-butyl ester, carboxylic acid or hydrogen on the thiophene ring resulted in modest reduction of inhibition activity, indicating that the ethylamide group is not essential 

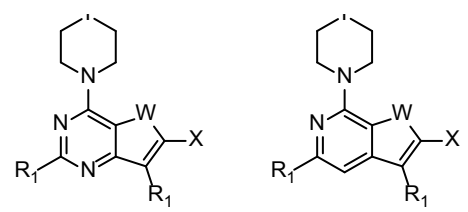<smiles>[R]c1nc2c([R])cc(N3CCCCC3)[n+]([X])c2nc1[R]</smiles>

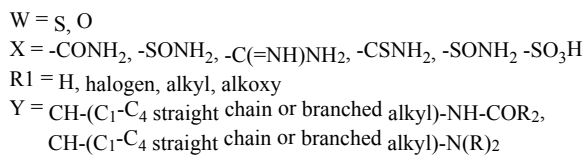

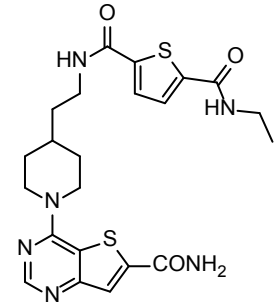

17

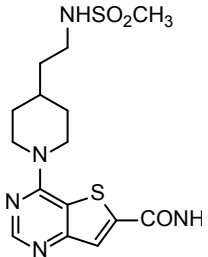

18

Figure 11: Substituted thieno[3,2-d]pyrimidin-6-carboxamide derivatives and analogues as SIRT1, SIRT2 and SIRT3 inhibitors.

Step 1<smiles>CCNC(=O)c1ccc(C(=O)OC)s1</smiles>
Step 2.

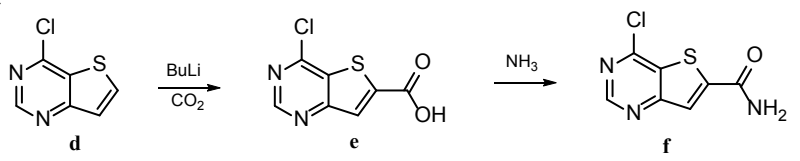

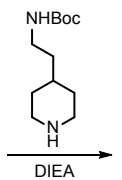<smiles>CC(C)(C)ONCCC1CCNCC1</smiles><smiles>NC(=O)c1cc2ncncc2s1</smiles>
Step 3.
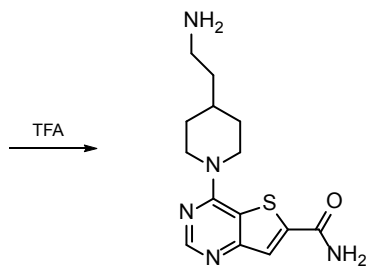

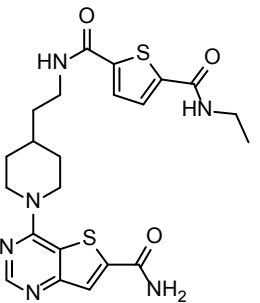

17

Scheme B: Synthesis of compound 17.

for activity. Whereas, a series of truncated derivatives indicated that the thieno[3,2-d]pyrimidine-6-carboxamide core alone was not sufficient for activity. Lastly, the thiophene was replaced with an acetamide group. To further optimize the potency a larger compound set was prepared wherein acetamide group replacement with a thioacetyl-, pivaloyl-, solfonamide or pyrrolydine group was explored. Compound 18 (Figure 11 and Table 1), bearing methylsolfonamide group, showed excellent potency with $\mathrm{IC}_{50}$ values of $4 \mathrm{nM}, 1 \mathrm{nM}$ and $7 \mathrm{nM}$ versus SIRT1, SIRT2 and SIRT3, respectively.

The patent described also the synthesis of the mentioned 
thieno[3,2-d]pyrimidine-6-carboxamide derivatives. Here we report the synthetic pathway of compound $\mathbf{1 7}$ (Scheme B) as an example. In the first step, to a solution of 5-(methoxycarbonyl)thiophene-2carboxylic acid (a) in DMF were added ethylamine hydrochloride, HATU and DIEA, the resulting mixture was stirred for $7 \mathrm{~h}$ to obtain methyl 5-(ethylcarbamoyl)thiophene-2-carboxylate (b). The methyl ester was hydrolyzed by $\mathrm{LiOH}$ to afford 5-(ethylcarbamoyl)thiophene2 -carboxylic acid as a white solid (compound c). In the second step, to a stirring solution of 2,2,6,6-tetramethylpiperidine and $\mathrm{BuLi}$ in THF was added 4-chlorothieno[3,2-d]pyrimidine (d) and dry ice at $-78^{\circ} \mathrm{C}$, to obtain 4 -chlorothieno[3,2-d]pyrimidine-6-carboxylic acid (e). Subsequently, the acid was converted into amide (f) by adding a solution of ammonia in dioxane. A solution of 4-chlorothieno[3,2-d] pyrimidine-6-carboxamide (f), tert-butyl(2-(piperidin-4-yl)ethyl) carbamate and DIEA in $\mathrm{CH}_{3} \mathrm{CN}$ was heated at reflux for $1 \mathrm{~h}$ to obtain tert-butyl(2-(1-(6-carbamoylthieno[3,2-d]pyrimidin-4-yl)piperidin4-yl)ethyl)carbamate (g). The tert-butyl group was removed by trifluoroacetic acid to give compound $\mathbf{h}$. In the last step, the coupling reaction between compound $\mathbf{c}$ and compound $\mathbf{h}$ was performed by adding DIEA and HATU in DMF, to afford compound $\mathbf{1 7 .}$

\section{Conclusions}

Since it was clarified that SIRT1 substrates are involved in a number of biological processes, as gene transcription, cell death and metabolism, SIRT1 has been considered an interesting target for treating a high number of diseases. Indeed, several patents focused on small molecules targeting SIRT1, both as activators or as inhibitors. Noteworthy, the patented compounds bear different chemical scaffolds, however in the considered patents the structural requirements for the effective modulating activity on SIRT-1 were not fully clarified. Given the interest on SIRT1 activators such as resveratrol, several studies on stilbene and polyphenol derivatives have been reported. Moreover, some terpenoid dilactones, analogues of strigolactone GR24, were reported as SIRT1 activators useful for the treatment of metabolic disorders. Nevertheless, most of the patented sirtuin modulators are aza-heterocycles, in particular imidazo-pyridazines, triazolopyridazines and pyrazolo-pyrimidines. Interestingly, since both activators and inhibitors are known to counteract viral replication, it's presumable that further studies in this area will lead to the development of new effective molecules. Regarding the SIRTs inhibition, it has been reported that thieno[3,2-d]pyrimidine-6-carboxamide derivatives, dual SIRT1 and SIRT2 inhibitors, showed antiproliferative activity. However, further investigations are needed for their development as anticancer agents. To conclude, the great number of patents on SIRT-1 modulators indicates the relevance of this target for new therapeutic strategies useful for the treatment of several kinds of diseases. Therefore, as a perspective, SIRT-1 modulators may reach a real application in therapy.

\section{References}

1. Sauve AA, Wolberger C, Schramm VL, Boeke JD (2006) The biochemistry of sirtuins. Annu Rev Biochem 75: 435-465.

2. Blander G, Guarente L (2004) The Sir2 family of protein deacetylases. Annu Rev Biochem 73: 417-435.

3. Nguyen GT, Gertz M, Steegborn C (2013) Crystal structures of Sirt3 complexes with 4'-bromo-resveratrol reveal binding sites and inhibition mechanism. Chem Biol 20: 1375-1385.

4. Zheng W (2013) Mechanism-based modulator discovery for sirtuin-catalyzed deacetylation reaction. Mini Rev Med Chem 13: 132-154.

5. Michishita E, Park JY, Burneskis JM, Barrett JC, Horikawa I (2005) Evolutionarily conserved and nonconserved cellular localizations and functions of human SIRT proteins. Mol Biol Cell 16: 4623-4635.
6. Onyango P, Celic I, McCaffery JM, Boeke JD, Feinberg AP (2002) SIRT3, a human SIR2 homologue, is an NAD-dependent deacetylase localized to mitochondria. Proc Natl Acad Sci USA 99: 13653-13658.

7. Newman JC, He W, Verdin E (2012) Mitochondrial protein acylation and intermediary metabolism: regulation by sirtuins and implications for metabolic disease. J Biol Chem 287: 42436-42443.

8. Michan S, Sinclair D (2007) Sirtuins in mammals: insights into their biological function. Biochem J 404: 1-13.

9. Alcain FJ, Villalba JM (2009) Sirtuin inhibitors. Expert Opin Ther Patents 19 283-294.

10. Kaeberlein M, McDonagh T, Heltweg B, Hixon J, Westman EA, et al. (2005) Substrate-specific activation of sirtuins by resveratrol. J Biol Chem 280: 1703817045.

11. Laakso $M$, Yaluri $N$ (2014) Composition and method for influencing energy metabolism and treating metabolic and other disorders. US20140142170.

12. Pillarisetti S (2008) A review of Sirt1 and Sirt1 modulators in cardiovascular and metabolic diseases. Recent Pat Cardiovasc Drug Discov 3: 156-164.

13. Choi Y, Um SJ, Park T (2013) Indole-3-carbinol directly targets SIRT1 to inhibit adipocyte differentiation. Int J Obes (Lond) 37: 881-884.

14. Blum CA, Ellis JL, Loh C, Ng PY, Perni RB, et al. (2011) SIRT1 modulation as a novel approach to the treatment of diseases of aging. J Med Chem 54 $417-432$.

15. London B, Irani KJ (2013) Regulation of cardiac sodium channels by sirt1 and sirt1 activators. WO2013166502.

16. Scuderi C, Stecca C, Bronzuoli MR, Rotili D, Valente S, et al. (2014) Sirtuin modulators control reactive gliosis in an in vitro model of Alzheimer's disease. Front Pharmacol 5: 89

17. Albani D, Polito L, Batelli S, De Mauro S, Fracasso C, et al. (2009) The SIRT1 activator resveratrol protects SK-N-BE cells from oxidative stress and against toxicity caused by alpha-synuclein or amyloid-beta (1-42) peptide. J Neurochem 110: 1445-1456.

18. Calliari A, Bobba N, Escande C, Chini EN (2014) Resveratrol delays Wallerian degeneration in a $\mathrm{NAD}(+)$ and $\mathrm{DBC} 1$ dependent manner. Exp Neurol 251: 91-100.

19. Herskovits AZ, Guarente L (2013) Sirtuin deacetylases in neurodegenerative diseases of aging. Cell Res 23: 746-758.

20. Cantó C, Auwerx J (2009) PGC-1alpha, SIRT1 and AMPK, an energy sensing network that controls energy expenditure. Curr Opin Lipidol 20: 98-105.

21. Rodgers JT, Lerin C, Haas W, Gygi SP, Spiegelman BM, et al. (2005) Nutrient control of glucose homeostasis through a complex of PGC-1alpha and SIRT1. Nature 434: 113-118.

22. Leibiger IB, Berggren PO (2006) Sirt1: a metabolic master switch that modulates lifespan. Nat Med 12: 34-36.

23. Lin J, Handschin C, Spiegelman BM (2005) Metabolic control through the PGC 1 family of transcription coactivators. Cell Metab 1: 361-370.

24. Wang Y (2014) Molecular Links between Caloric Restriction and Sir2/SIRT1 Activation. Diabetes Metab J 38: 321-329.

25. Villalba JM, Alcaín FJ (2012) Sirtuin activators and inhibitors. Biofactors 38 349-359.

26. Baur JA (2010) Biochemical effects of SIRT1 activators. Biochim Biophys Acta 1804: 1626-1634.

27. Saunders LR, Verdin E (2007) Sirtuins: critical regulators at the crossroads between cancer and aging. Oncogene 26: 5489-5504.

28. Shih J, Donmez G (2013) Mitochondrial sirtuins as therapeutic targets for agerelated disorders. Genes Cancer 4: 91-96.

29. Koyuncu E, Budayeva HG, Miteva YV, Ricci DP, Silhavy TJ, et al. (2014) Sirtuins are evolutionarily conserved viral restriction factors. MBio 5.

30. Li WY, Ren JH, Tao NN, Ran LK, Chen X, et al. (2016) The SIRT1 inhibitor nicotinamide, inhibits hepatitis $B$ virus replication in vitro and in vivo. Arch Virol 161: $621-630$

31. Shenk T, Koyuncu E, Kim H, Cristea I, MacMillan D (2015) Methods for modulating sirtuin enzymes. US20150335657. 
Citation: Graziadio A, Locatelli A, Morigi R, Rambaldi M (2016) Small-Molecules Targeting Sirtuin 1: A Patent Review (2012-2015). Med chem (Los Angeles) 6: 411-421. doi:10.4172/2161-0444.1000378

32. Höppner S, Schänzer W, Thevis M (2013) Fragmentation studies of SIRT1activating drugs and their detection in human plasma for doping contro purposes. Rapid Commun Mass Spectrom 27: 35-50

33. Langley E, Pearson M, Faretta M, Bauer UM, Frye RA, et al. (2002) Human SIR2 deacetylates p53 and antagonizes PML/p53-induced cellular senescence. EMBO J 21: 2383-2396.

34. Inoue A, Fujimoto D (1970) Histone deacetylase from calf thymus. Biochim Biophys Acta 220: 307-316

35. Nayagam VM, Wang X, Tan YC, Poulsen A, Goh KC, et al. (2006) SIRT1 modulating compounds from high-throughput screening as anti-inflammatory and insulin-sensitizing agents. J Biomol Screen 11: 959-967.

36. Rye PT, Frick LE, Ozbal CC, Lamarr WA (2011) Advances in label-free screening approaches for studying sirtuin-mediated deacetylation. J Biomol Screen 16: 1217-1226.

37. Milne JC, Lambert PD, Schenk S, Carney DP, Smith JJ, et al. (2007) Small molecule activators of SIRT1 as therapeutics for the treatment of type 2 diabetes. Nature 450: 712-716.

38. Marcotte PA, Richardson PR, Guo J, Barrett LW, Xu N, et al. (2004) Fluorescence assay of SIRT protein deacetylases using an acetylated peptide substrate and a secondary trypsin reaction. Anal Biochem 332: 90-99.

39. Boss O, Worcester S, Iffland A, Smith J, Milne J, et al. (2012) Biomarkers of sirtuin activity and methods of use thereof. US20100215632.

40. Chi BV (2012) Quinazolinone and related analogs as sirtuin modulators. US20120165330.

41. Laakso M, Yaluri N (2012) Composition and method for influencing energy metabolism and treating metabolic and other disorders. WO2012056113.

42. Besserer A, Bécard G, Jauneau A, Roux C, Séjalon-Delmas N (2008) GR24, a synthetic analog of strigolactones, stimulates the mitosis and growth of the arbuscular mycorrhizal fungus Gigaspora rosea by boosting its energy metabolism. Plant Physiol 148: 402-413.

43. Pall ML (2014) Nutritional supplements and associated treatment methods US20140031299.

44. Lagouge M, Argmann C, Gerhart-Hines Z, Meziane H, Lerin C, et al. (2006)
Resveratrol improves mitochondrial function and protects against metabolic disease by activating SIRT1 and PGC-1alpha. Cell 127: 1109-1122.

45. Larsen BD, Andersen S, Larsen MS (2013) Novel heterocyclic compounds useful in sirtuin binding and modulation. WO2013090369.

46. Blum CA, Springer SK, Vu CB (2013) Substituted bicyclic aza-heterocycles and analogues as sirtuin modulators. WO2013059589.

47. Blum CA, Disch JS, Springer SK (2013) Substituted bicyclic aza-heterocycles and analogues as sirtuin modulators. WO2013059594.

48. Casaubon RL, Narayan R, Oalmann C, Vu CB (2013) Substituted bicyclic azaheterocycles and analogues as sirtuin modulators. WO2013059587.

49. Blum CA, Oalmann C, Szczepankiewicz BG, Caldwell RD, Casaubon R, et al (2014) Substituted bridged urea analogs as sirtuin modulators. WO2014186313.

50. Hamuro Y, Coales SJ, Southern MR, Nemeth-Cawley JF, Stranz DD, et al (2003) Rapid analysis of protein structure and dynamics by hydrogen/deuterium exchange mass spectrometry. J Biomol Tech 14: 171-182.

51. Bitzer J, Kuper T, Wabnitz P (2014) Carboxylated stilbenes for activating AMPK and sirtuins. EP2801357.

52. Pan Y, Middleton RP (2012) Methods for regulating sirtuin gene expression. WO2012141876.

53. Buchwald-Werner SB, Büter Berger K (2015) Mangifera indica as a sirtuin 1 activating agent. WO2015158836.

54. Banks AS, Kon N, Knight C, Matsumoto M, Gutiérrez-Juárez R, et al. (2008) SirT1 gain of function increases energy efficiency and prevents diabetes in mice. Cell Metab 8: 333-341.

55. Peck B, Chen CY, Ho KK, Di Fruscia P, Myatt SS, et al. (2010) SIRT inhibitors induce cell death and p53 acetylation through targeting both SIRT1 and SIRT2. Mol Cancer Ther 9: 844-855.

56. Baur JA, Ungvari Z, Minor RK, Le Couteur DG, de Cabo R (2012) Are sirtuins viable targets for improving healthspan and lifespan? Nat Rev Drug Discov 11 443-461.

57. Disch JS, Evindar G, Chiu CH, Blum CA, Dai H, et al. (2013) Discovery of thieno[3,2-d]pyrimidine-6-carboxamides as potent inhibitors of SIRT, SIRT2, and SIRT3. J Med Chem 56: 3666-3679. 